\title{
NC MACHINING METHOD OF CONCAVE-CONVEX ARC GEAR
}

\author{
Jian-ping Wang ${ }^{1}$ \\ ${ }^{1}$ Changsha Aeronautical Vocational and Technical College, Hunan, China \\ Email: wangjianping cs1d3@126.com
}

\begin{abstract}
In order to improve production efficiency and reduce processing costs, the special NC milling method of concave-convex arc gear is further studied, which provides theoretical basis for the design of special NC machine tool for concave-convex arc gear. A special NC machining method is proposed to modify the existing NC machine tools. The concave-convex arc gears are machined and kinematics experiments are carried out. The results show that the modified machine tools can achieve the desired processing objectives, and the prototype of concave-convex arc gears is machined by the modified machine tools. It can be seen that the feasibility and rationality of the design of special CNC machine tool for linear gears are verified by the comparison of processing time, motion simulation and roughness test.
\end{abstract}

Keywords: NC Machining; Concave-Convex Arc Gear; Special Processing Method; Special Machine Tool for Linear Gear.

\section{Introduction}

Gear is the most widely used key basic components. Gear industry is one of the technology-intensive industries in machinery industry. At present, gear industry has become the largest industry in China. In 2016, the output value of China's gear industry is about 230 billion yuan, ranking first in the world, but some key parts still need to be imported [1]. At the 2017 China Gear Industry Congress and CGMA Annual Meeting, Wang Changlu, Secretary-General of Gear Association, analyzed the problems existing in China's gear industry, especially pointed out that the main problem was the serious inadequacy of gear basic research and independent innovation ability [2]. The lack of key basic research will lead to the lack of support for the development of gear product design and related manufacturing technology. The weak independent innovation ability of the gear industry results in a large number of high-end gear products depending on imports, and the core technology is restricted by others [3].

Based on the research of current general NC technology, the feasibility of using general NC technology to process concave-convex arc gear is analyzed, a general NC processing method of concave-convex arc gear is put forward, and the concave-convex arc gear sample is successfully processed by this method [4].

A special NC machining method for concaveconvex arc gear is presented [5]. According to the meshing principle of concave-convex arc gear and the structural characteristics of main and driven wheels of concave-convex arc gear, a special NC milling method for concave-convex arc gear is studied and established [6].

In order to enlarge the application scope of line gear in the field of medium and small power transmission with conventional size, and to improve the strength of line gear, a design theory and numerical control processing method of concaveconvex arc gear are proposed, which provides a theoretical basis for the design of special NC machine tool for line gear [7].

\section{Experimental Procedure}

The concave-convex arc gear mechanism includes the driving gear and the driven gear [8]. As shown in figure 1 , the axes of the driving gear and the driven gear form a pair of transmission pairs at a certain angle in the same plane. The active contact line is a spatial cylindrical helical curve, forming a pair of spatial co-rolling curves with the driven contact line [9].

The normal tooth profile of the concave-convex arc gear pair at the meshing point is a pair of internal tangent arcs.

The active contact line is a space cylindrical helical curve. Its equation in coordinate system is formula (1).

$$
\left\{\begin{array}{c}
x_{M}^{(1)}=m \cos t \\
y_{M}^{(1)}=m \sin t \\
z_{M}^{(1)}=n \pi+n t
\end{array}\right.
$$

Among them, $\mathrm{m}$ is the helical radius of the space cylindrical helical curve. $n$ is the pitch parameter of 
the space cylindrical helical curve, and $\mathrm{n}=\frac{\mathrm{p}}{2 \pi} \cdot \mathrm{t}$ is a parametric variable, and $t \in\left[t_{s}, t_{e}\right] . \Delta t=t_{e}-t_{s}$, $t_{s}=-\pi-\frac{\Delta t}{2}$, and $t_{e}=-\pi+\frac{\Delta t}{2}$, which means the coincidence degree condition can be satisfied. $\varepsilon=\frac{\Delta t \times N_{1}}{2 \pi} \geq 1, \mathrm{~N}_{1}$ is the number of teeth of the driving wheel.

Therefore, $\varepsilon, \mathrm{N}_{1}, \mathrm{~m}$, and $\mathrm{n}$ are the key parameters of active contact line.

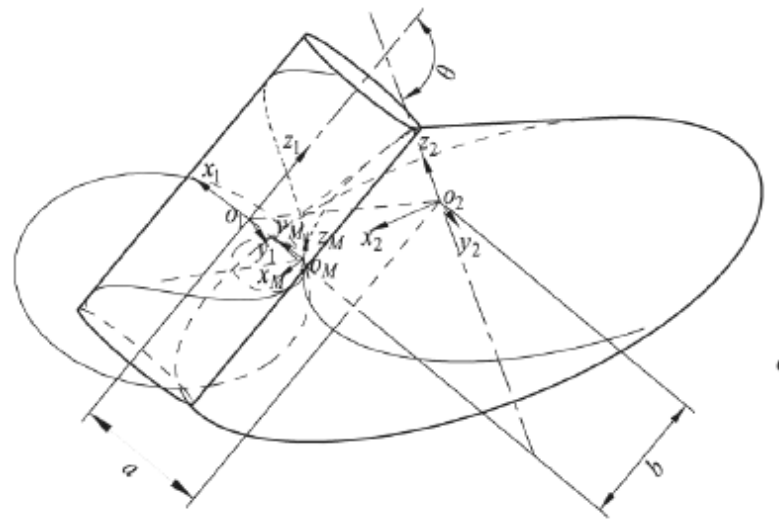

(a)

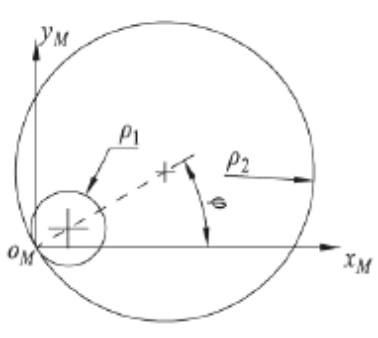

(b)

Figure 1: Diagram of a pair of concave-convex arc tooth profiles at the meshing point

The follower contact line is a space curve which is in conjunction with the contact line of the driving wheel. Its equation in the coordinate system is formula (2).

$$
\left\{\begin{array}{c}
x_{M}^{(2)}=[(m-a) \cos \theta-(n \pi+n t-b) \sin \theta] \cos \frac{t+\pi}{i_{12}} \\
y_{M}^{(2)}=[(m-a) \cos \theta-(n \pi+n t-b) \sin \theta] \sin \frac{t+\pi}{i_{12}} \\
z_{M}^{(2)}=(m-a) \sin \theta-(n \pi+n t-b) \cos \theta
\end{array}\right.
$$

Among them, $i_{12}$ is the transmission ratio between the driving wheel and the driven wheel, and $i_{12}=\frac{N_{2}}{N_{1}}$. From figure $1(\mathrm{a})$, it can be seen that a and $b$ are the components of the center distance of the two gears in the direction of $x_{1}$ and $z_{1}$ axes, and $a=\left(1-i_{12}\right) m$. Their values can be determined by formulas (3) and (4).

$$
\begin{aligned}
& \left\{\begin{array}{c}
a=\left(1-i_{12} \cos \theta\right) m \\
b=(m-a) \tan \theta
\end{array}\right. \\
& \left\{\begin{array}{c}
a=m \\
b=i_{12} m
\end{array}\right.
\end{aligned}
$$

$\theta$ is the angle between the angular velocity of the driving wheel and the angular velocity of the driven wheel, and $\theta \in[0, \pi]$. When $\theta \neq \frac{\pi}{2}$, the values of a and $\mathrm{b}$ are derived from formula (3).
When $\theta=\frac{\pi}{2}$, the values of a and $\mathrm{b}$ are derived from formula (4). Therefore, $i_{12}, \theta, \mathrm{a}, \mathrm{b}, \mathrm{m}$ and $\mathrm{n}$ are the key parameters of the active contact line.

\section{Results and Discussion}

\subsection{Structure and processing principle of concave-convex curved gear}

The concave-convex arc gear mechanism is a new type of gear mechanism. Unlike the traditional gear line contact meshing, it is a point contact meshing transmission gear mechanism, and its line tooth structure has different characteristics. There is a pair of spatial conjugate curves on the surface of a pair of meshing line gear teeth. The processing of concaveconvex arc gear is mainly to ensure the accuracy of this pair of spatial conjugate curves, and to ensure the consistency of the tooth profile between the active gear and the driven gear. It has a normal concave or convex circular arc profile. The concaveconvex arc gear mechanism studied here has a cylindrical body for the driving gear and a cylindrical, conical or circular body for the driven gear. In order to make the gear pair have better transmission characteristics, the processing of concave-convex arc gear needs to combine its meshing principle and structural characteristics.

According to the meshing characteristics of the contact line of concave-convex arc gear, the motion law of each axis and its mathematical expression of 
the machine tool for processing concave-convex arc gear are studied and obtained.

Finally, a milling method of concave-convex arc gear based on the principle of imaginary workpiece is proposed.

\subsection{The structure and processing principle of the drive line gear}

The shape of the main line gear of concaveconvex arc gear is cylindrical, and its structure is shown in figure 2 . The contact line of the driving gear is set as a space cylindrical helix.

The convex tooth profile distributes along the normal direction of the contact line.

The line teeth of the driving gear are composed of the main teeth surface 4 , the top teeth surface 5 and the pair teeth surface 6 .

Active contact line 1 is located on the main tooth surface, which is the track line of meshing point on the active gear teeth.

The first tooth thickness auxiliary line 2 is located inside the tooth. The second tooth thickness auxiliary line 3 is located on the surface of the secondary teeth. Its main function is to assist the formation of linear teeth in design.

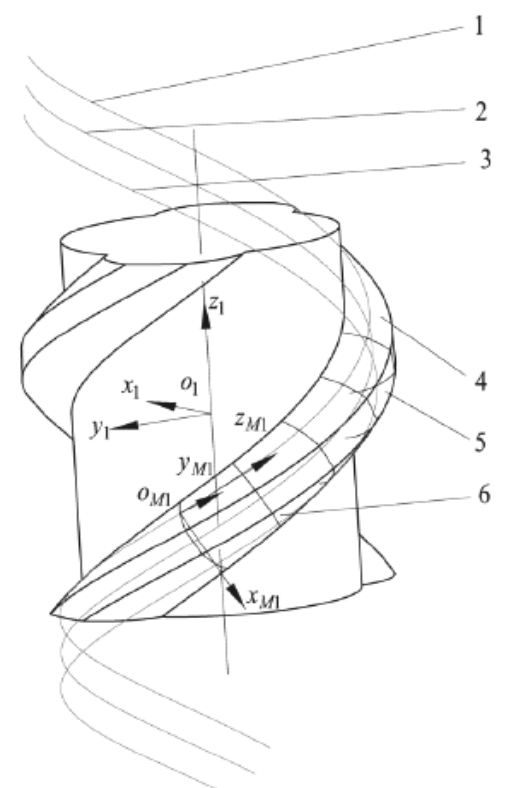

Figure 2: Structural schematic diagram of drive gear

The processing of the drive gear conforms to the meshing principle of the concave-convex arc gear. If there is a pair of concave-convex arc gears engage, and the meshing points move in a straight line along the generatrix of the revolving surface where the contact line is located.

When machining the driving gear, the driven wheel is replaced by the cutter.

The locating point of the cutter is the same as that of the meshing point.
The linear motion of the cutter is consistent with that of the meshing point. The rotary motion of the billet is the same as that of the drive gear.

Finally, under the action of cutting, the tooth profile curve of the billet surface is a space cylindrical helix.

The profile forming of the driving gear is completed by the finger shaped milling cutter.

The arc parameters of the axial profile of the milling cutter are the same as those of the tooth profile of the driving gear.

The position relationship between the finger shaped milling cutter and the drive gear is shown in figure 3. $\lambda_{1}$ is the spiral angle of the active contact line. The plane $x_{M 1} O_{M 1} y_{M 1}$ is the normal plane of the point $O_{M 1}$ on the active contact line.

The axis of the milling cutter is located on the plane $x_{M 1} O_{M 1} y_{M 1}$.

When the main tooth surface 4 is machined, the forming milling cutter is located on the side of the normal tooth profile with meshing points.

When the tooth surface of the pair 6 is machined, the forming milling cutter moves to the other side of the normal tooth profile.

The linear motion of the cutter and the rotary motion of the billet remain unchanged when the two sides of the tooth surface are machined separately.

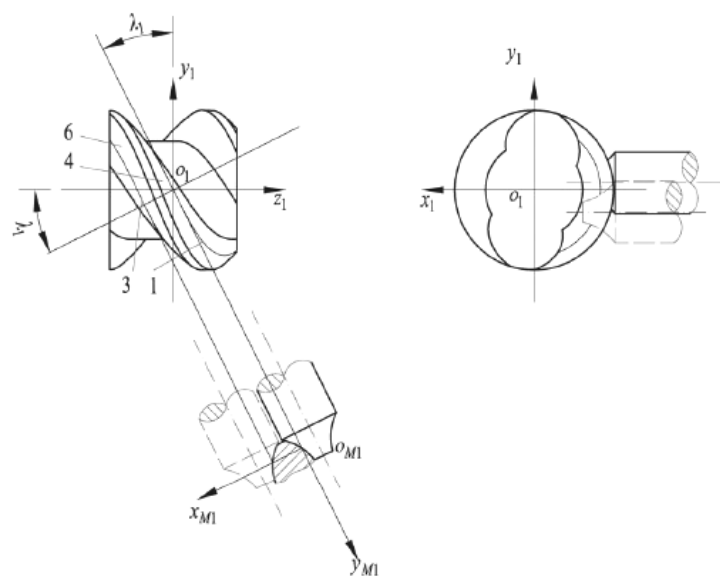

Figure 3: The milling sketch of the drive gear

\subsection{Follower gear processing method based on space curve meshing principle}

When processing bevel gears, imaginary plane gears or flat top gears are used as imaginary parts, and the cutter head is equivalent to one tooth of imaginary parts. The principle of imaginary workpiece is applied to the processing of driven gear of concave-convex arc gear.

The imaginary workpiece of concave-convex arc gear is equivalent to another form of drive gear. It has similar structural characteristics with the active 
gear, including active contact line, convex profile and the formation of gear teeth.

Through active contact line, it can form meshing relationship with driven gear.

Unlike the active gear, the normal profile of the workpiece is assumed to coincide with that of the driven gear at the meshing point. When processing follower gear, the tooth profile of the imaginary workpiece is equivalent to the motion track of the finger-shaped milling cutter on the imaginary workpiece wheel.

The processing method of driven gear is simplified by using the principle of imaginary workpiece. On the wheel body of the imaginary workpiece, the tool trajectory is consistent with the active contact line. At the meshing point, the cutter replaces the imaginary workpiece. Combining with the meshing motion of concave-convex arc gear, the profile surface of follower gear is cut by forming milling cutter on the blank of follower gear.

Based on the principle of imaginary workpiece, the required arbitrary follower contact line can be obtained indirectly on the surface of the follower billet.

This processing method is suitable for driven gear with arbitrary shape.
When processing driven gear, the position relationship between the imaginary workpiece and the driven wheel is shown in figure 4 .

$\theta$ is the angle between the angular velocity of the imaginary workpiece and the driven gear. Point $\mathrm{M}$ is the meshing point.

The cylindrical wheel with follower contact line 7-1 and the circular wheel with follower contact line 7-2 are special cases when the values are $180^{\circ}$ and $90^{\circ}$, respectively. In figure 4 (a), the active contact line 1 and the driven contact line 7 are a pair of spatial conjugate curves. Active contact line 1 and driven contact line 7-1 are also a pair of spatial coincidence curves. In figure 4 (b), the active contact line 1 and the driven contact line 7-2 are a pair of spatial coincidence curves.

The follower contact line 7-2 is a plane curve, which coincides with the profile of the follower gear in figure 4 (a). From figure 4, it can be seen that different driven gear can be machined only by slightly changing the processing parameters of the driving gear.

At this time, the linear motion parameters of the meshing point remain unchanged, and the slave gear billet needs to be rotated at a certain angle.

The rotary motion of the slave gear billet meets the requirements of the transmission ratio.

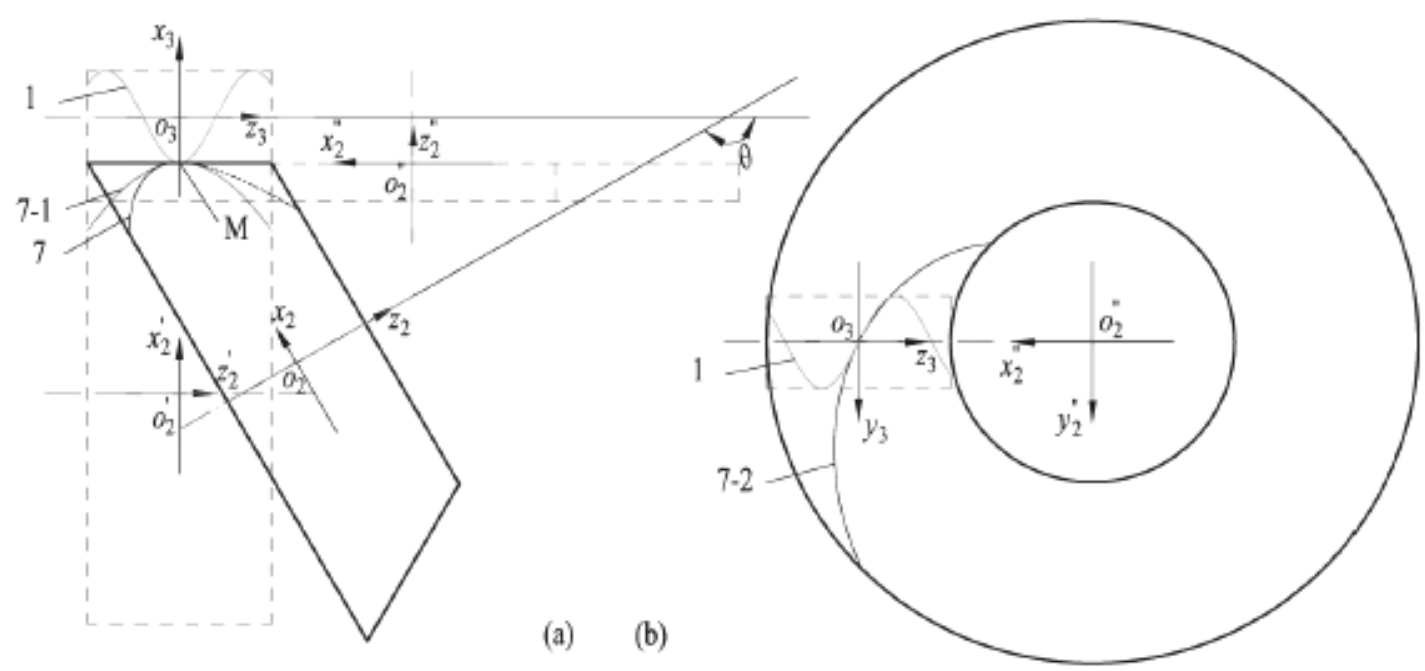

Figure 4: Position relationship between driven gear and imaginary workpiece

\subsection{The structure and processing principle of the driven line gear}

The shape of the follower gear is conical, cylindrical and circular, as shown in figure 4. The contact line between the driven gear and the active gear is a pair of spatial coincidence curves. Its structure is shown in figure 5 . The tooth of driven line gear is composed of main tooth surface 10 , bottom tooth surface 11 and pair tooth surface 12 .
The follower contact line 7 is located on the main tooth surface 10 , which is the track of the meshing point on the follower gear.

The first tooth thickness auxiliary line 8 is located between the driven contact line 7 and the second tooth thickness auxiliary line 9.

The second tooth thickness auxiliary line 9 is located on the surface of the secondary teeth, and its main function is to form the gear teeth. 


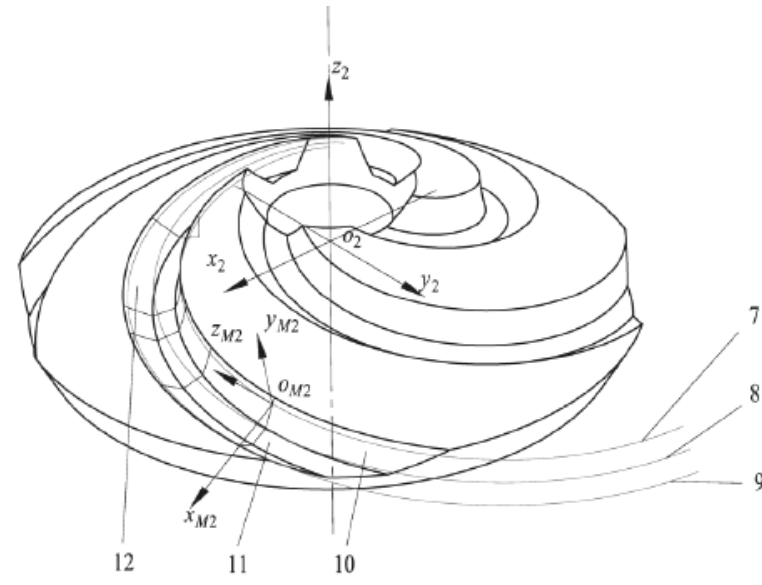

Figure 5: Structural schematic diagram of driven gear

The driven line gear is machined according to the principle of one imaginary part. The relevant processing parameters include the position parameters of the tool, the linear motion parameters of the tool and the rotary motion parameters of the billet. When processing driven gear, the positioning point of the cutter is the same as the meshing point, and the linear motion of the cutter is the same as the linear motion of the meshing point. It is assumed that the rotational motion of the workpiece is the same as that of the driving gear. That is to say, the slave gear blank rotates at a specified angle and rotates according to the designed transmission ratio.

These motions are combined with the rotary cutting motion of the forming milling cutter, and the follower profile is formed on the surface of the follower gear blank.

The parameters of the axial profile arc of the forming milling cutter are the same as those of the follower gear.

The position relationship between finger shaped milling cutter and imaginary workpiece and follower gear is shown in figure 6 when processing follower gear. On the normal plane of the active contact line at the meshing point, it is assumed that the tooth profile of the machined part coincides with that of the driven gear. $O_{M 2}$ and $O_{M 3}$ are the contact points at the meshing points of the driven gear and the imaginary workpiece, respectively. $\lambda_{1}$ is the spiral angle of the active contact line.

Planes $x_{M 2} O_{M 2} y_{M 2}$ and $x_{M 3} O_{M 3} y_{M 3}$ are normal planes at the meshing points on the active contact line, and the milling cutter axis is located on the normal plane. When the main tooth surface 10 of driven gear is machined, the forming milling cutter is located on the side of the normal tooth profile with meshing points. When the tooth surface 12 of the pair is machined, the forming milling cutter moves to the other side of the normal tooth profile.

The linear motion of the cutter and the rotary motion of the billet remain unchanged when the two sides of the tooth surface are machined separately.
In the processing of driven gear, the function of the imaginary part is mainly to reflect the position relationship between the cutter and the blank, as shown in figure 7.

If there is a meshing motion between a cylindrical wheel body and a driven gear in the machining process, the motion trajectory of the cylindrical wheel body and the forming milling cutter can form a hypothetical workpiece.

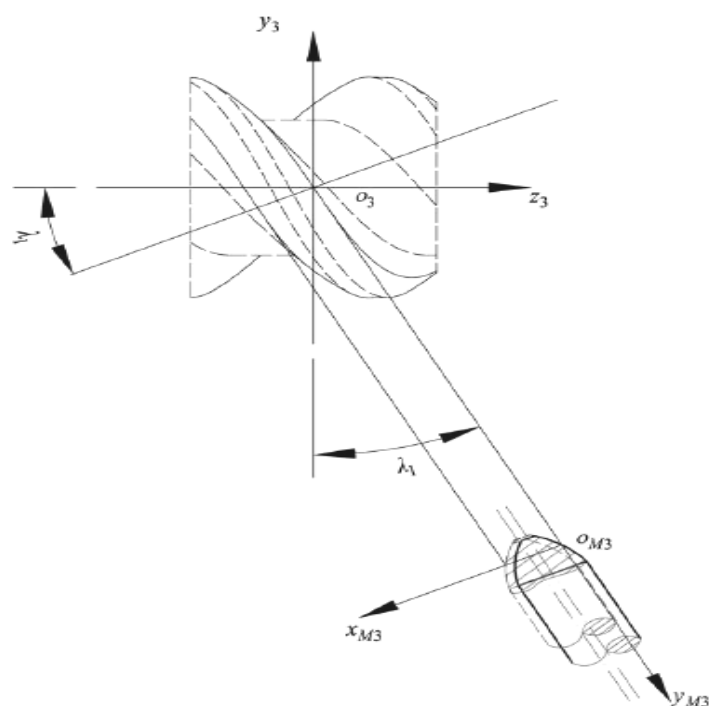

Figure 6: Tool position diagram for processing driven gear

The feed motion of the special milling machine is the combination of the A-axis and X-axis motion when processing the drive gear. The trajectory of the meshing point on the billet in the meshing process of concave-convex arc gear is the active contact line.

Therefore, the motion law of axle A and axle X can be deduced from the mathematical expression of the active contact line when machining the driving gear. In figure 3, the coordinate system can be regarded as the workpiece coordinate system when the drive gear is machined. The corresponding relationship between the coordinate system and the machine tool coordinate system is shown in figure 7.

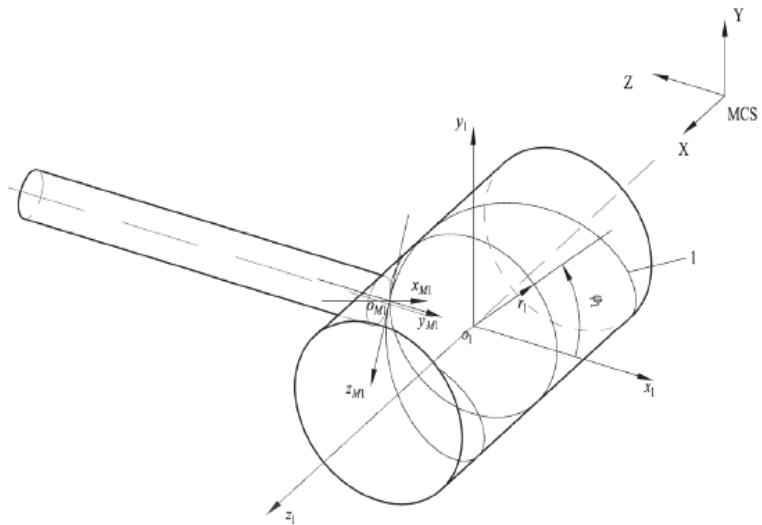

Figure. 7 The corresponding relationship between workpiece coordinate system and machine tool coordinate system when machining the drive gear 
The equation of active contact line 1 in coordinate system is formula (5).

$$
\left\{\begin{array}{c}
x_{M}^{(1)}=m \cos t \\
y_{M}^{(1)}=m \sin t \\
z_{M}^{(1)}=n \pi+n t
\end{array}\right.
$$

In the formula, $\mathrm{m}$ is the helical radius of the space cylindrical helical curve. $\mathrm{n}$ is the pitch parameter of the space helical curve, and pitch $p=2 \pi n$. $\mathrm{t}$ refers to the variable, and $t \in\left[t_{s}, t_{e}\right] . \Delta t=t_{e}-t_{s}$, $t_{s}=-\pi-\frac{\Delta t}{2}$, and $t_{e}=-\pi+\frac{\Delta t}{2}$ meet the coincidence condition $\xi=\frac{\Delta t \times Z_{1}}{2 \pi} \geq 1 . \mathrm{Z}_{1}$ is the number of teeth of the driving gear.

When the rectangular coordinate system is transformed into the cylindrical coordinate system, the active contact line equation of the drive gear is equation (6).

$$
\left\{\begin{array}{c}
r_{M}^{(1)}=m \\
\phi_{M}^{(1)}=t \\
z_{M}^{(1)}=n \pi+n t
\end{array}\right.
$$

Formula (6) shows that there is a definite mathematical relationship between the angular displacement and the axial displacement of any point on the active contact line on the cylindrical surface with radius $\mathrm{m}$. In the coordinate system $o_{1}-x_{1} y_{1} z_{1}$, the laws of motion of the A-axis and the X-axis are expressed as $\phi_{1}$ and expressed as $z_{1}$, and the relation between $\phi_{1}$ and $z_{1}$ satisfies the formula (7).

$$
\left\{\begin{array}{c}
\phi_{1}=t \\
z_{1}=n \pi+n t
\end{array}\right.
$$

In figure 3, when the main tooth surface 4 of the driving gear is machined, the joint motion parameters of the $\mathrm{A}$-axis and the $\mathrm{X}$-axis are $\phi_{1}$ and $z_{1}$. According to the forming principle of the line teeth of the active line gear, the tooth surface of the active line gear is the set of the normal tooth profile at the meshing point. Therefore, only the position parameters of the milling cutter need to be changed when machining the bevel face of the drive gear 6 .

\section{Conclusion}

A design theory of concave-convex arc gear is presented. The concave-convex arc gear is based on the principle of space curve meshing.

The application of linear gear is mainly extended to the power transmission field of medium and small power $(0.5-5 \mathrm{kw})$ of conventional size (20-200mm).
The concave-convex arc gear studied is a special type of linear gear, which can realize the transmission of intersecting axes.

The special NC machining method of concaveconvex arc gears studied is based on the space meshing theory of linear gears. Therefore, this method can also be applied to the manufacturing of other types of linear gears in a certain range. Compared with the general NC machining method, this method mainly changes the way of realizing the relative movement of tool and workpiece. On the one hand, it is easier to achieve the accuracy of movement and has higher reliability.

On the other hand, it is not only limited to the processing of concave-convex arc gear, but also suitable for the NC processing of other similar shape mechanical parts.

\section{References}

[1] Shen X Y, Liu X, Jia-Cheng H U, et al. Simulation Researchon Tip-Enhanced Raman Scattering Effect of Concave Arc Tipwith Silver-coated. Acta Photonica Sinica, 2017, 46(10), pp. 142-148.

[2] Naik H, Harikrishnan S, Tiwari S. Numerical investigations on heat transfer characteristics of curved rectangular winglet placed in a channel. International Journal of Thermal Sciences, 2018, 129, pp. 489-503.

[3] Chen Y, Li Y. Design formulae for a concave convex arc line gear mechanism. Mechanical Sciences, 2016, 7(2), pp. 209-218.

[4] Klasztorny M, Nycz D B, Szurgott P. Modelling and simulation of crash tests of N2-W4-A category safety road barrier in horizontal concave arc. International Journal of Crashworthiness, 2016, 21(6), pp. 644-659.

[5] Leonardi G P, Pratelli A. On the Cheeger sets in strips and non-convex domains. Calculus of Variations \& Partial Differential Equations, 2016, 55(1), pp. 15.

[6] Xie W, Fan C, Yang C, et al. Effect of acoustic field parameters on arc acoustic binding during ultrasonic wave-assisted arc welding. Ultrasonics Sonochemistry, 2016, 29, pp. 476-484.

[7] Naik H, Harikrishnan S, Tiwari S. Numerical investigations on heat transfer characteristics of curved rectangular winglet placed in a channel. International Journal of Thermal Sciences, 2018, 129, pp. 489-503.

[8] Zhu C, Cheon J, Tang X, et al. Effect of swing arc on molten pool behaviors in narrow-gap GMAW of 5083 Al-alloy. Journal of Materials Processing Technology, 2018, 259, pp. 243-258.

[9] Nguepnang M A, Boer M, Kim T. Stagnation Heat Transfer on a Concave Surface Cooled by Unconfined Slot Jet. Journal of Thermophysics \& Heat Transfer, 2016, 30(3), pp. 1-9. 